\title{
Energy requirements of adults
}

\author{
Prakash Shetty* \\ Public Health Nutrition Unit, Department of Epidemiology and Population Health, London School of Hygiene \\ and Tropical Medicine, 49-51 Bedford Square, London WC1B 3DP, UK
}

\begin{abstract}
Objectives: To describe issues related to energy requirements of free living adults and discuss the importance of basal metabolic rate (BMR) and their relationships to total energy expenditure (TEE) and physical activity level (PAL, derived as TEE/BMR) and to determine the influence of body weight, height, age and sex.

Design: Based on a review of the literature, this paper examines the variability in BMR due to methodology, ethnicity, migration and adaptation (both metabolic and behavioural) due to changes in nutritional status. Collates and compiles data on measurements of TEE in free living healthy adults, to arrive at limits and to compare TEE of populations with different life-styles.

Results and Conclusions: The constancy of BMR and its validity as a reliable predictor of TEE in adults as well as the validity of PAL as an index of TEE adjusted for BMR and thus its use to categorise the physical activity pattern and lifestyle of an individual was confirmed. The limits of human daily energy expenditure at around $1.2 \times$ BMR and $4.5 \times$ BMR based on measurements made in free living adults have been reported in the literature. A large and robust database now exists of energy expenditure measurements obtained by the doubly labelled water method in the scientific literature and the data shows that, in general, levels of energy expenditure are similar to the recommendations for energy requirements adopted by $\mathrm{FAO} / \mathrm{WHO} / \mathrm{UNU}$ (1985). The review also confirms that metabolic adaptation to energy restriction is not an important factor that needs to be considered when recommending energy requirements for adults in developing countries.
\end{abstract}

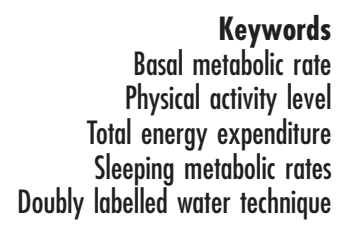

\section{Introduction}

The Joint Food and Agricultural Organization/World Health Organization/United Nations University (FAO/ WHO/UNU) Expert Consultation on energy and protein requirements ${ }^{1}$ adopted the principle of relying on estimates of energy expenditure rather than energy intake from dietary surveys to estimate the energy requirements of adults. Obtaining data on energy expenditure of adult males and females has thus gained importance. Since the available reliable data on measurement of habitual energy expenditure in free-living adults has been limited hitherto, measures and or predictions of the basal metabolic rate (BMR) have gained great importance. In this chapter several issues related to BMRs of adults, its relationship to the total energy expenditure (TEE) and the physical activity levels (PAL) and how they influence the estimation of adult energy requirements are discussed. These include the methodology of BMR measurement, variability of BMR and TEE and the constancy of BMR over time in adults. A discussion on the usefulness and limitations of equations for the prediction of BMR from anthropometric parameters such as body weight and the likelihood of ethnic variations in BMR and the effects of migration are also included. The background document also deals with metabolic adaptation and discusses the relevance of this to estimating adult energy requirements. It concludes with a discussion on the factorial approach to assessing TEE by the use of PAL and provides a review of the published data, to date on doubly labelled water (DLW) measurements of TEE and PAL of free-living healthy adults. It suggests ways in which the new data although largely from adults in developed, industrialised countries may be used to derive other indicators of levels of physical activities of adults.

\section{BMR factorial approach to estimating energy requirements of adults}

Since BMR constitutes between 60 and $70 \%$ of the TEE, BMR now forms the basis of the factorial approach for the estimation of TEE of adults (both men and non-pregnant, non-lactating women) in the assessment of energy requirements of adults. BMR of an individual can simply be defined as the minimal rate of energy expenditure compatible with life'. It is measured under standard 
conditions of immobility in the fasted state (12-14 hours after a meal) in an ambient environmental temperature of between 26 and 30 degrees centigrade, which ensures no activation of heat generating processes such as shivering. It can be quantified by direct or indirect calorimetric techniques; the former measuring the heat output directly, while the latter measures the oxygen consumption and carbon-dioxide production which are then appropriately converted to their energy equivalents. BMR can also be predicted with reasonable accuracy (i.e. with a coefficient of variation of $8 \%$ ) in adults using predictive equations.

\section{Methodological aspects of BMR measurement in adults}

Whether the methods or techniques used to measure the BMR of adults contribute to variability in BMRs is a question that needs to be addressed if BMRs are the basis for estimating TEE by the factorial method. BMR measurements involve in the first instance an estimation of the oxygen consumption of the individual, which is then converted into units of heat or energy output. In general most investigators involved in BMR measurements use a range of techniques available to estimate oxygen consumption, which provide more or less the same results. Comparisons of techniques using different equipment such as Douglas bags, Oxylogs, Metabolators, and ventilated hoods demonstrate that there are no significant differences between estimates of oxygen consumption of adults obtained by two or more techniques in the same individual at the same time ${ }^{2,3}$. However, more recent comparisons of BMR measurements in 18-30-year-old men using the Deltatrac (open-circuit) and Benedict Roth spirometer (closed-circuit using oxygen) suggested that closed-circuit methods gave a higher BMR value, $(+5.6 \%)^{4}$ reinforcing the general belief that closed-circuit apparatus tended to give higher values than the currently in vogue more sophisticated open-circuit systems.

During the subsequent conversion of oxygen consumption values (in milliliters or litres of oxygen) to energy output or expenditure (in kcals or kJ or MJ) many assumptions are made which may influence the final estimate of the BMR. The most important of these assumptions are:

1. The value attributed to the non-protein respiratory quotient (NPRQ or RQ) when the method used does not actually measure the NPRQ by not measuring the $\mathrm{CO}_{2}$ production.

2. The equations used in the calculations to convert $\mathrm{O}_{2}$ consumption and $\mathrm{CO}_{2}$ production when measured (whether or not Nitrogen excretion in the urine is estimated) into units of energy output.

3. The corrections that are made for differences in the volumes of inspired and expired air when both $\mathrm{CO}_{2}$ output and $\mathrm{O}_{2}$ consumption are measured.

It is specially believed that these assumptions do not influence the final results over the range of physiological RQs observed. This, however, is not correct. The difference between the true NPRQ of the subject and the assumed RQ (be it 0.82 or 1.0) in the calculation can introduce an error of over 5\% if the true RQ is as low as 0.77 for the same measure of $\mathrm{O}_{2}$ consumption in a subject ${ }^{5}$ (Table 1). When an Oxylog which assumes an RQ $=1$ is used and the true RQ of the subject is less than 0.8, the difference in the estimate of energy expenditure is reported to be of the order of as much as $4.6 \%{ }^{6}$. Brockway $^{7}$ conclusively demonstrated that differences in the final estimate of BMR due to the various formulae used in the conversion of $\mathrm{O}_{2}$ consumption values, i.e. those of Weir ${ }^{8}$; Consolazio, et al. ${ }^{9}$; Brouwer ${ }^{10}$; and Passmore and Eastwood $^{11}$ may extend over a range of about $3 \%$. McLean ${ }^{12}$ has argued that the not uncommon assumption

Table 1 Sources of error in conversion of oxygen consumption to energy output between assumed and true respiratory quotients (RQs). *

\begin{tabular}{|c|c|c|c|c|c|}
\hline \multirow[b]{2}{*}{ True $R Q$} & \multicolumn{2}{|c|}{ Error in volume of $\mathrm{O}_{2}$ consumed ${ }^{\dagger}$} & \multirow{2}{*}{$\begin{array}{l}\text { Error caused by caloric } \\
\text { value of the RQ used in } \\
\text { equation }(\%)\end{array}$} & \multicolumn{2}{|c|}{ Net error in energy } \\
\hline & Uncorrected volume & Corrected volume ${ }^{\ddagger}$ & & Uncorrected volume & Corrected volume \\
\hline \multicolumn{6}{|c|}{ Assumed $R Q=0.82$ in equation } \\
\hline Eq. $1 \mathrm{RQ}=0.71$ & -7.1 & -2.7 & +2.6 & -4.5 & -0.1 \\
\hline Eq. $2 \mathrm{RQ}=0.79$ & -5.3 & -0.8 & +0.7 & -4.6 & -0.1 \\
\hline Eq. $3 R Q=0.82$ & -4.5 & 0 & 0 & -4.5 & 0 \\
\hline Eq. $4 \mathrm{RQ}=0.94$ & -1.6 & +3.1 & -2.7 & -4.3 & +0.4 \\
\hline Eq. $5 \mathrm{RQ}=1.00$ & 0 & +4.8 & -4.0 & -4.0 & +0.8 \\
\hline \multicolumn{6}{|c|}{ Assumed $R Q=1.0$ in equation } \\
\hline Eq. $1 \mathrm{RQ}=0.71$ & -7.1 & - & +6.8 & -0.3 & - \\
\hline Eq. $2 R Q=0.79$ & -5.3 & - & +4.8 & -0.5 & - \\
\hline Eq. $3 R Q=0.82$ & -4.5 & - & +4.1 & -0.4 & - \\
\hline Eq. $4 \mathrm{RQ}=0.94$ & -1.6 & - & +1.3 & -0.3 & - \\
\hline Eq. $5 R Q=1.00$ & 0 & - & 0 & 0 & - \\
\hline
\end{tabular}

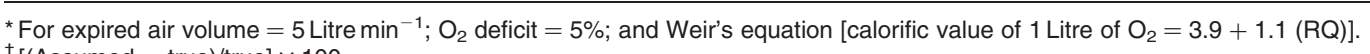

${ }^{\dagger}[($ Assumed - true $) /$ true $] \times 100$.

${ }^{\ddagger}$ Corrected volume indicates the value of $\mathrm{O}_{2}$ consumed that has been corrected for difference in inspired and expired volume at the given $\mathrm{RQ}$. 
that $\mathrm{O}_{2}$ consumption $=$ outlet ventilation $\times \mathrm{O}_{2}$ concentration difference, can introduce an error in the estimate of $\mathrm{O}_{2}$ consumption of the order of $\pm 6 \%$. This large error emphasises the importance of correcting for differences in volume flow of inspired and expired air when measuring BMR. McLean ${ }^{12}$ also states that this large error is fortunately cancelled out by an error in the calorific value of $\mathrm{O}_{2}$ consumed as the RQ of the subject varies. However, this is not necessarily true. For example, the calculation of energy output from values for an $\mathrm{O}_{2}$ deficit of, say, 5\%, for a fixed volume of 5 litres per minute at an assumed RQ of 0.82 using Weir's formula introduces a net error of between +4.5 and $-4.0 \%$ for a range of physiological RQs of between 0.71 and 1.0, respectively ${ }^{5}$.

Given the errors that arise as a result of the assumptions made during the conversion and final calculation of BMR (in kcals or $\mathrm{kJ}$ ) from measures of $\mathrm{O}_{2}$ consumption (in millilitres or litres), even with the tacit assumption that the measures of $\mathrm{O}_{2}$ consumption are fairly accurate in themselves, implies that differences in BMR between individuals or groups of individuals of the order of $5 \%$ do not have biological significance unless the methodology, the assumptions made and the calculations used to arrive at the BMR values are comparable. It is of course assumed that certain stipulated minimal experimental prerequisites such as absence of gross muscular activity, a postabsorptive state, thermo-neutral environment, etc. are strictly met in order to ensure basal levels of metabolism so that measurements made between individuals or in the same individual over time are comparable and that biological significance can be imparted to differences that are observed under these conditions.

\section{Influence of physical activity on BMR}

In the 1990s, there was a spate of publications highlighting the role of physical activity on body composition and metabolic rate (both resting/basal as well as sleeping) and TEE; elegantly reviewed recently by Westerterp ${ }^{13}$. Comparisons of highly trained endurance athletes with untrained controls seems to indicate that in metabolic facility conditions, during weight maintenance having refrained from physical activity for at least 2 days prior to measurement, there are no significant differences between athletes $(n=20)$ and non-athletes $(n=43)$ in their BMRs, Sleeping Metabolic Rates (SMR) before or after adjusting for differences in body composition ${ }^{14}$. Both groups compared were of the same sex (males) and no differences were found between maximal aerobic capacity and metabolic rate when adjusted for differences in body composition, i.e. fat and fat free mass (FFM). However, reports to the contrary have also been published more recently although in a very limited number (four each in both sexes) of elite endurance athletes ${ }^{15}$. The athletes were shown to have significantly higher BMR than predicted from body mass or body composition. The athletes had 13\% higher BMR than controls related to FFM and 16\% higher if related both to FFM and fat mass and they also demonstrated a lower RQ indicating higher levels of fat oxidation. Several studies conducted recently on the effects of endurance training seem to support the view that PAL do not significantly influence either BMR or $\mathrm{SMR}^{16-19}$. The small decrease if any seen in both metabolic parameters is related to the changes in body composition consequent to the endurance training supporting other observations that a higher level of physical activity is related to a lower percent of body fat ${ }^{20}$. These studies in general suggest that exercise training has no chronic long-term effect on SMR or BMR. Since PAL and their ratio to BMRs, i.e. PAL are an important aspect of assessing requirements the overall evidence that levels of physical activity do not influence BMR is reassuring when BMR factorial approaches are generally recommended for estimating the energy requirements of adults.

\section{Variability in adult BMR}

\section{Inter-individual variability}

It is generally recognised that in a group of apparently healthy and comparable individuals there is a considerable between-individual or inter-individual variation in habitual, total daily energy expenditure. This, however, is not known to be as large as the inter-individual variation in energy intakes. Edholm ${ }^{21}$ reviewed a number of studies where repeated measurements of TEE had been made and reported that the coefficient of inter-individual variability was of the order of $\pm 12.5 \%$ on a body weight basis. In recent studies where energy and expenditure were measured in a respiratory chamber and where both the intake and the PAL were controlled, the coefficient of variation (CV) of inter-individual variation ranged between 7.5 and $17.9 \%{ }^{22,23}$. It appeared that the $\mathrm{CV}$ depended upon the variations in body size; the larger the variation in body weight among subjects, the larger the CV of TEE.

Comparisons of CVs of subjects of similar body weight and body composition shows that the $\mathrm{CV}$ of the interindividual variability of BMR was $13 \%{ }^{24}$. Other reports suggest that the inter-individual CV of BMR varies between 7.9 and $12.0 \%$ in both male and female subjects when measured under conditions of controlled intake and physical activity ${ }^{23,25,26}$. The inter-individual CV of BMR was $9.2 \%$ when intake was controlled at two levels of physical activity in males ${ }^{27}$ and of the order of $11.7 \%$ in free-living males who had a CV of body weights of $15.2 \% 5$. In the few instances where the CVs of inter-individual variation in BMR and TEE have been simultaneously computed (in male subjects who maintained body weight) they show the CVs were of the order of $10.2 \%$ and $10.3 \%$, respectively $^{28}$. This last report emphasises that the CV of inter-individual variability of TEE is reflected in the CV of 
Table 2 Intra-individual variations in BMR and TEE

\begin{tabular}{|c|c|c|}
\hline & Sex & CV (\%) \\
\hline \multicolumn{3}{|l|}{$B M R$} \\
\hline Energy intake and physical activity controlled ${ }^{24}$ & $\mathrm{~F}$ & 2.0 \\
\hline Energy intake controlled; physical activity varied ${ }^{27}$ & M & 2.2 \\
\hline Energy intake varied; physical activity controlled ${ }^{28}$ & M & 2.8 \\
\hline Energy intake and physical activity uncontrolled ${ }^{31}$ & M & 2.9 \\
\hline \multicolumn{3}{|l|}{ TEE (24 hour) } \\
\hline \multicolumn{3}{|l|}{ Energy intake and physical activity controlled } \\
\hline Dallosso et al. ${ }^{28}$ & M & 1.5 \\
\hline Webb and Abrams ${ }^{32}$ & $\mathrm{~F}$ & 3.3 \\
\hline Webb and Annis ${ }^{33}$ & $\mathrm{~F}$ & 6.0 \\
\hline Garby et al. ${ }^{22}$ & M & 2.2 \\
\hline De Boer ${ }^{23}$ & $\mathrm{~F}$ & 1.9 \\
\hline \multicolumn{3}{|l|}{ Energy intake varied; physical activity controlled } \\
\hline De Boer ${ }^{23}$ & $\mathrm{~F}$ & 2.4 \\
\hline De Boer ${ }^{23}$ & $\mathrm{~F}$ & 2.6 \\
\hline
\end{tabular}

$\overline{\text { BMR - basal metabolic rate; TEE - total energy expenditure; CV - coeffi- }}$ cient of variation.

BMR since the latter makes a substantial contribution to the total energy output of an individual.

\section{Intra-individual variability in BMR}

Sukhatme and Margen ${ }^{29}$ argued that within-individual variations in intakes are more important than betweenindividual variations, and that the observed inter-individual variations can largely be explained in terms of the intraindividual variations. These investigators consider that the well-documented variation in intakes observed among apparently healthy individuals indulging in similar levels of activity is evidence that different individuals operate at different levels within what they consider to be the intraindividual range of 'costless' adaptation. This has resulted in an unsubstantiated claim that intra-individual variations in energy expenditure are also large, with a wide CV even in subjects accustomed to similar levels of physical activity every day, and that this wide variation needs to be considered when assessing the energy requirements of an adult $^{30}$. Table 2 summarises some of the recent data on the within-individual variations in BMR obtained from repeated measurements in the same individual when: (1) energy intake and physical activity have been controlled while in a respiration chamber ${ }^{24}$; (2) energy intake alone was controlled and BMR measurements were made on two levels of physical activity over a 24-hour period ${ }^{27}$; (3) physical activity was kept constant over 24 hours but the energy intake was varied at two different levels ${ }^{28}$; and (4) when BMR measurements have been made in free-living subjects in whom neither intake nor activity have been regulated $^{31}$. The $\mathrm{CV}$ of the measured BMR has never exceeded $5 \%$ and is frequently below $3 \%$.

Estimation of the CV of 24-hour energy expenditure measurements using whole body calorimetry also leads to similar conclusions (Table 2). Several studies ${ }^{22,23,28,32,33}$ have confirmed the low CV of intra-individual differences in 24-hour energy output when both energy intake and physical activity are tightly regulated as is usual in a calorimetry protocol. Even when energy intakes are varied at two different levels, but the activity patterns when inside the calorimeter are maintained constant, the withinindividual CVs do not vary by more than 2.4 or $2.6 \%{ }^{23}$. When energy intakes are unaltered, but 24-hour energy expenditure is varied at two different levels of activity in the same subject, a large CV (of the order of 9.8\%) is seen. This is to be expected since the 24-hour energy output has been deliberately altered in these subjects. However, even in these experimental situations, the CVs of the measured BMR in the same subjects at the two different levels of activity while in the calorimeter is no more than $2.2 \%{ }^{27}$.

The intra-individual variation (CV\%) of TEE obtained from repeated measurements based on DLW studies where body weight, activity and physiological status are unaltered have also recently been compiled. Data from nine such studies are summarised here and confirm that the $\mathrm{CV} \%$ is reasonably small despite measurements being made using DLW in the free-living state ${ }^{34}$. The mean within-CV of 79 individuals in whom more than one DLW measurement has been made was $8.9 \%$ (Table 3). This includes both the methodological error and the variation in activity levels. The overwhelming recent evidence tends to support the view that intra-individual variations in BMR

Table 3 Within subject CV in DLW measurement of total energy expenditure where activity, weight and physiological status are unchanged

\begin{tabular}{|c|c|c|c|}
\hline Subjects & No. of subjects & No. of measurements & CV \\
\hline $\begin{array}{l}\text { Adolescents confined to a metabolic facility during two periods of experimental } \\
\text { diet. No control on activity }\end{array}$ & 9 & 2 & 6.8 \\
\hline Twice in the calorimeter with the same imposed exercise & 4 & 2 & 9.1 \\
\hline Mothers measured pre-pregnant and at 16 weeks of pregnancy & 9 & 2 & 7.4 \\
\hline Mothers in weeks 4,8 and 12 of lactation & 10 & 3 & 7.9 \\
\hline $\begin{array}{l}\text { Males living in a metabolic facility but following normal occupation. First and } \\
\text { last measurements at same weight and activity }\end{array}$ & 8 & 2 & 8.1 \\
\hline Males living in metabolic facility but pursuing usual sedentary occupation & 7 & 3 & 7.1 \\
\hline Physiotherapy students. No apparent change in activity & 5 & 2 & 10.5 \\
\hline Free-living men & 17 & 2 or 3 & 11.0 \\
\hline Free-living men during two experimental diets & 10 & 2 & 10.9 \\
\hline Mean of nine studies & & & 8.9 \\
\hline
\end{tabular}

CV - coefficient of variation; DLW - doubly labelled water. 
Table 4 Intra-individual variations in $\mathrm{BMR}\left(\mathrm{MJ} \mathrm{day}^{-1}\right)$ with time

\begin{tabular}{|c|c|c|c|c|c|c|}
\hline & \multirow[b]{2}{*}{ Sex } & \multirow[b]{2}{*}{$n$} & \multicolumn{4}{|c|}{ Coefficient of variation (\%) } \\
\hline & & & Days & Weeks & Months & Years \\
\hline Jequier and Schutz ${ }^{24}$ & $\mathrm{~F}$ & 14 & 2 & & & \\
\hline \multirow[t]{2}{*}{ Garby and Lammert ${ }^{22}$} & M & 22 & 2.4 & & & \\
\hline & M & 23 & & 2.2 & & \\
\hline \multirow[t]{2}{*}{ Lammert et al. ${ }^{37}$} & M & 7 & 3.5 & 4.3 & & \\
\hline & M & 7 & & 4.8 & & \\
\hline Soares and Shetty ${ }^{31}$ & M & 5 & & 3.1 & & \\
\hline \multirow[t]{2}{*}{ Soares and Shetty ${ }^{38}$} & M & 5 & & 2.9 & & \\
\hline & M & 10 & & & 2.5 & \\
\hline Henry et al. ${ }^{36}$ & M & 9 & & & & 4.0 \\
\hline
\end{tabular}

BMR - basal metabolic rate.

of the same subject are small and probably insignificant even when neither the intakes nor the activity patterns of the individual are controlled. Reports of BMR measurements seem thus to support the conclusion that the withinsubject variations in BMR, even when energy intake and physical activity are uncontrolled, are indeed very small and insignificant ${ }^{35}$.

\section{The constancy of BMR of adults over time}

A critical analysis of the historical data on the variations in BMR over long periods of time indicates that the BMR of an individual is constant over time ${ }^{35,36}$. More recent data also confirms this feature of the constancy of BMR in adult individuals (Table 4). Recent measurements of BMRs in 14 subjects (controls and obese), each tested on 5 consecutive days, have confirmed that the CV is low, at around $2 \%^{24}$ and 166 male subjects studied on two separate occasions had a $\mathrm{CV}$ of less than $3 \%^{28}$. Other studies ${ }^{22,31,36-38}$ have supported the view that the intraindividual variations in BMR measured over a period of days, weeks or even months or years, is small and probably not significant.

A critical analysis of the variations seen in BMRs or in 24-hour energy output over a period of 2 years when intakes and activity patterns were not controlled over this length of time is represented in Table 5. The BMRs of 10 male subjects measured on a minimum of three occasions over a period of 6-36 months showed a mean CV of intraindividual differences (separated from measurement error) of the order of $2.5 \%{ }^{38}$. Five of the 10 individuals who had body weight changes of $>2.0 \%$ had even smaller CVs (1.8\%) as compared to those who had smaller changes in body weight over the period of time (Table 5). Measurements of 24 hour expenditure by calorimetry in 10 females over a period of 24 months has also shown small CVs of 2.4\%; however smaller CVs were seen in those five women who had $<2 \%$ body weight change over this period $^{23}$. In these females, neither intakes nor activity patterns were controlled, except during the periods when they were strictly on the calorimetry regimes. These recent data confirm the conclusions that BMRs of individuals are relatively constant over a period of several years despite reasonable fluctuations in body weight, when no attempt is made to regulate either energy intake or physical activity patterns.

\section{Predicting BMRs of adults to estimate requirements}

Conventionally, BMR is measured using direct or indirect calorimetry and although BMR may be accurately measured using these techniques, it is simpler, in practice, to use predictive equations. By 1951, a plethora of equations were in existence to predict BMR, some equations being easier to use than others. The predictive equations of Aub and Du Bois $^{39}$ tended to overestimate BMR as the subjects measured by these authors were under thermal stress and anxious. In contrast, the Robertson and Reid equations ${ }^{40}$ underestimated BMR as the equations were based on the lowest values of metabolism recorded in their subjects. Finally, while Quenouille's analysis ${ }^{41}$ was comprehensive, the equations were too complicated to be of routine practical use. It is important to remember that the measurement of BMR in patients, attempts to normalise

Table 5 Intra-individual variations in energy expenditure and body weight over time

\begin{tabular}{|c|c|c|c|c|}
\hline \multirow[b]{2}{*}{ Group } & \multirow[b]{2}{*}{$n$} & \multirow[b]{2}{*}{ Time interval'(months) } & \multicolumn{2}{|c|}{ CV (\%) } \\
\hline & & & EE & Body weight \\
\hline \multicolumn{5}{|l|}{$\mathrm{BMR}^{\dagger}$} \\
\hline \multicolumn{5}{|l|}{ Males } \\
\hline Entire & 10 & $18.2 \pm 2.3(7.0-33.0)$ & 2.5 & 2.5 \\
\hline Weight stable $\neq$ & 5 & $14.4 \pm 2.9(7.0-21.0)$ & 3.2 & 0.6 \\
\hline Weight change & 5 & $22.0 \pm 3.0(15.0-33.0)$ & 1.8 & 4.3 \\
\hline \multicolumn{5}{|l|}{24 hour EE" } \\
\hline \multicolumn{5}{|l|}{ Females } \\
\hline Entire & 10 & $9.5 \pm 2.0(2.0-24.0)$ & 2.4 & 2.4 \\
\hline Weight stable $\neq$ & 5 & $7.2 \pm 2.0(2.0-13.0)$ & 2.0 & 1.1 \\
\hline Weight change & 5 & $11.8 \pm 3.3(5.0-24.0)$ & 2.7 & 4.1 \\
\hline
\end{tabular}

CV - coefficient of variation; BMR - basal metabolic rate.

*Mean \pm sem; figures in parenthesis = range.

†Soares and Shetty, 1987.

${ }^{\ddagger}$ Considered stable if change $<2.0 \%$ of initial body weight.

"De Boer, 1985 (recalculated). 
BMR to some variable of the body such as body surface area and attempts to predict both or more variables from simple measures such as weight and height were driven by clinical considerations. Much of the work until the 1950s on BMRs were largely related to their use as a laboratory aid in the diagnosis of hyper and hypo metabolic states mainly associated with thyroid dysfunction.

Recently Schofield ${ }^{42}$ presented predictive equations for both sexes for the following age groups: $0-3,3-10,10-18$, $18-30,30-60$ and $>60$ years. This analysis forms the basis of the equations used by the $\mathrm{FAO} / \mathrm{WHO} / \mathrm{UNU}$ report $^{1}$ on energy and protein requirements. More importantly, BMR measurements and their use remained a clinical curiosity until Schofield's analysis ${ }^{42}$ and the FAO/WHO/UNU report ${ }^{1}$ transformed their use and utility. BMR now became the fundamental basis for estimating energy requirements in man. The Schofield analysis and equations based on a database of 114 published studies of BMR, representing 7173 data points, is the largest and most comprehensive analysis of BMR to date. While the Schofield equations predict BMR accurately in many individuals from the temperate climate, they seem to be less accurate in predicting BMR in tropical populations ${ }^{43,44}$ and North Americans ${ }^{4}$. In fact, the Schofield equations may appear to overestimate BMR in many populations ${ }^{44-46}$. Although an analysis of the BMR of people from the Tropics and sub-Tropics such as Indians, Chinese, Indonesians, Malaysians, Javanese, Japanese, Filipinos, Ceylonese, Africans, Hawaiians, Samoans, Mayans and South Americans ${ }^{43}$ point to a lower BMR than predicted by the Schofield equations, the bias imposed by the dominance of Italian data is likely to annul this difference. More recent data in fact supports the view that BMRs of people in the tropics are not different from those in temperate regions, i.e. North Americans/Europeans, provided the subjects are well nourished $^{44,45,47,48}$. However, there is also evidence in the literature that supports the view that even in populations of developed countries like Australia, the Schofield equations overestimate BMR. The measured BMR of Australian men and women were similar to the predicted BMR using the equations of Hayter and Henry ${ }^{46}$ while the Schofield equations were not valid for the prediction of BMR of young Australian men $(n=39)$ and women $(n=89)$. There is thus evidence to suggest that the Schofield equations may be overestimating BMR in many populations, leading to an overestimation of their energy requirements.

It is important to appreciate both the strengths and limitations of the Schofield predictive equations. However, a case has been made that there may appear to be a need to re-analyse the more recent well documented worldwide data on BMR using stringent inclusion criteria in order to generate better valid equations to predict BMR in humans worldwide. In 1981, Durnin (FAO/WHO) made a comprehensive survey of the BMR literature in an attempt to use weight, age and sex alone to predict BMR.
Subsequently Schofield ${ }^{42}$ extended this analysis and produced a series of predictive equations based on body weight since he found that the addition of height did not contribute much to improve the prediction. These formed the basis for the equations used in the FAO/WHO/UNU document Energy and Protein Requirements ${ }^{1}$. While Schofield's analysis has served a significant role in reestablishing the importance of using BMR to predict human energy requirements, recent workers have questioned the universal validity and application of these equations ${ }^{44,46,49-51}$. A recent analysis of the data from 96 Indians and 81 Caucasian Australians of both sexes, aged 18-30 showed that the equation based only on FFM accurately predicted the BMR of Indian men, Indian women and Australian men ${ }^{52}$. The authors of this study strongly support the use of FFM, rather than body weight, for the prediction of BMR in population groups of varying body size and composition. This, they believe, would allow an accurate estimation of BMR and hence energy requirements in population groups worldwide. The suggestion that FFM would be a better predictor of BMR or resting energy expenditure (REE) as suggested does have its problems too. Increasingly there is awareness of the fact that FFM is not a homogeneous entity and is made up of a large proportion of less metabolically active muscle mass at rest and variable but less proportions of metabolically active non-muscle tissue (organ mass) and these would influence the prediction of BMR or REE ${ }^{53,54}$. The more important question however, from the point of application of BMR prediction equations is the practical issue of estimating FFM in population groups, which unlike body weight, is far more difficult to obtain in practice.

\section{Ethnic differences and effects of international migration on BMR}

\section{Are ethnic differences relevant to the estimation of energy requirements?}

In addition to the observation that the Italian data revealed a higher BMR kg-1 in this group, Quenouille et al. ${ }^{41}$ and subsequently Schofield and others ${ }^{55}$ noted that Asiatic subjects (Indians and Chinese) had a BMR 10-12\% lower than Europeans. Mukkerjee and Gupta ${ }^{56}$ and Krishnan and Vareed $^{57}$ first reported such a claim for a lower BMR for Indians. Extending the observations reported by Schofield et al. ${ }^{55}$, Henry and Rees ${ }^{43,58}$ showed that the BMR was lower in a range of tropical residents (Filipino, Indian, Japanese, Brazilian, Chinese, Malay and Javanese) by $8-10 \%$ and was therefore not unique to Indian subjects alone. In contrast to these reports of low BMR in tropical peoples, recent studies have shown no difference in BMR between Indians and Europeans ${ }^{45,47,48}$. One approach to studying this problem is to compare the BMR in different population groups at similar body weights; thus eliminating a major source of variance in BMR associated with 
body weight. With this objective in mind, BMR predictive equations generated for different population groups over defined body weight ranges may then be used to compare BMR in these groups. To achieve this, the databases of Schofield, et al. ${ }^{55}$ and Henry and Rees ${ }^{58}$, were combined and used for analysis ${ }^{46}$. The resultant dataset contained 7737 individual measurements of body weight, height, sex, age, and the geographical origin of subjects. The 18-30 year age group was considered most suitable for detailed analysis as it had a BMR database of 2999 males and 874 females. This age range also demonstrated a negligible effect of age on BMR. Sub-samples of Indian (210 males and 137 females), Chinese (200 males and 122 females), North American/North European ( 478 males and 372 females) and Italians (169 males and 135 females) were also available for analysis.

Comparisons of linear regression equations derived for populations specific to sex and geographic origin show Italian males and females to be the most divergent group. It is apparent that Italians comprise $45 \%$ of the Schofield database (Table 6), upon which the present FAO/WHO/ UNU BMR predictive standards ${ }^{1}$ are based. Italians had significantly higher BMRs than all the other groups. In fact Schofield ${ }^{42}$ noted that when Italians were isolated from the rest of the sample and compared with the derived BMR predictive equation there was a significant lack of fit. However, they were included with North Europeans and Americans to derive the BMR predictive equations. The apparently elevated BMR of Italians, and their numerical dominance of total sample size appear to bias the predictive equations (Table 6). This may explain why even the more recently reported BMR of Indians is overestimated by the Schofield equations (Indian females by Piers and Shetty ${ }^{44}$; Indian males by Soares, Francis and Shetty ${ }^{45}$ ) since the much larger Italian group would bias the predictive equation for estimation of BMR. A few more recent studies of BMR measurements in Chinese adults ${ }^{59,60}$ also support the view that the current predictive equations including Schofield's overestimate BMRs of Chinese adults. Liu and others ${ }^{59}$ produced a predictive equation including both weight and height based on measurements of BMR and body composition in 102 men and 121 women in Taiwan. The subsequent study on adults from Hong Kong also showed that the Liu equations best predicted the BMRs of Chinese ${ }^{60}$.

The scientific literature on possible ethnic differences in energy metabolism is also aimed at exploring the causes of differences in the prevalence of obesity among certain population groups at increased risk of obesity. Rush and others $^{61}$ compared adult New Zealanders of European and Polynesian origin. TEE correlated with body weight in all but the obese adults of Polynesian origin. The study also reported that non-obese Polynesians expended 50\% more energy in physical activity than non-obese Europeans. Another report on adults over 55 years from the USA showed that African-Americans expended 10\% less energy than Caucasians ${ }^{62}$. Other studies in this area are confined to comparisons of Caucasian children with that of Pima Indians ${ }^{63}$ and African-Americans ${ }^{64,65}$. The results are equivocal and mixed and do not provide a clear evidence of ethnic differences.

\section{Effects of migration from tropical to temperate climate on BMR}

An analysis of the available literature on the effects of recent migration (i.e. over 2-4 weeks) from the tropics to temperate climate and up to 9 months later have shown that there are no differences of any significance in the BMR per kg body weight of tropical migrants compared to their temperate born and resident peers (Table 7). There seems to be no consistent trend of either a higher or lower value for BMR adjusted to body weight among the migrants from the tropics to temperate climate. The majority of the studies find BMR kg ${ }^{-1}$ body weight to be similar between tropical migrants and temperate residents provided the subjects are from privileged backgrounds and are well nourished. There is no reason to believe the wellnourished tropical individuals have a BMR lower than that of European or North American subjects although reports

Table 6 List of Italian subjects used in the database of Schofield

\begin{tabular}{lllll}
\hline Study & $n$ & Sex & Age & \\
\hline Pepe and Rinaldi (1936) & 217 & M & $6-16$ & None provided \\
& 143 & F & $5-12$ & None provided \\
Pepe and Perrelli (1937) & 257 & M & $5-16$ & None provided \\
& 235 & F & $5-12$ & None provided \\
Felloni (1936) & 532 & M & $19-25$ & Students of the Royal Fascist Academy \\
Lafralla (1937) & 213 & M & $14-20$ & Students of Naples Royal Military College \\
Lenti (1937) & 525 & M & $20-25$ & Military servicemen \\
Pepe (1938) & 252 & M & $18-24$ & Students of Royal Naval Academy \\
Occhiulo and Pepe (1939) & 247 & F & $20-67$ & Various social groups \\
Occhiulo and Pepe (1940) & 571 & M & $22-54$ & Police officers \\
Granall and Busca (1941-42) & 186 & M & $16-55$ & Labourers and miners \\
Total & 3370 & & & \\
\hline
\end{tabular}

All references in Schofield, Schofield and James ${ }^{55}$. 
Table 7 Recent studies of BMR in male migrants from tropical to temperate climate

\begin{tabular}{|c|c|c|c|c|c|c|c|}
\hline \multirow{2}{*}{$\begin{array}{l}\text { Study } \\
\text { DeBoer et al. (1988) }\end{array}$} & \multirow{2}{*}{$\begin{array}{l}\text { Subjects } \\
\text { African }\end{array}$} & \multirow{2}{*}{$\frac{n}{8}$} & \multirow{2}{*}{$\frac{\text { Age }}{31}$} & \multirow{2}{*}{$\frac{\text { Height }(\mathrm{m})}{1.71}$} & \multirow{2}{*}{$\frac{\text { Weight }(\mathrm{kg})}{69.9}$} & \multicolumn{2}{|c|}{$\mathrm{kJ} \mathrm{kg}^{-1}$ per day } \\
\hline & & & & & & 91 & SMR \\
\hline & European & 7 & 30 & 1.84 & 78.4 & 87 & SMR \\
\hline & Chinese & 7 & 33 & $62.5^{\star}$ & $1.67^{*}$ & $98^{*}$ & SMR \\
\hline & Indian & 8 & 26 & $58.9^{*}$ & $1.72^{*}$ & $98^{*}$ & SMR \\
\hline \multirow[t]{2}{*}{ Henry et al. (1987) } & Asian & 11 & 21 & 1.63 & 56.2 & 115 & RMR \\
\hline & British & 11 & 25 & 1.68 & 57.4 & 108 & RMR \\
\hline \multirow[t]{2}{*}{ Ulijaszek and Strickland (1991) } & Gurkhas & 17 & 25 & $1.67^{\star \star}$ & 67.1 & 105 & BMR \\
\hline & British & 17 & 23 & 1.73 & 66.8 & 110 & BMR \\
\hline \multirow[t]{3}{*}{ Geissler and Aldouri (1985) } & British & 15 & 25 & 1.74 & 68.1 & 117 & RMR \\
\hline & Asian & 15 & 27 & 1.68 & 63.9 & $107^{\star \star \star}$ & RMR \\
\hline & African & 15 & 28 & 1.71 & 67.1 & $101^{\star \star *}$ & RMR \\
\hline \multirow[t]{2}{*}{ Blackwell et al. (1985) } & American & 8 & 31 & 1.75 & 75.0 & 93 & SMR \\
\hline & Asian & 8 & 25 & $1.66^{*}$ & $53.0^{*}$ & 108 & SMR \\
\hline \multirow[t]{2}{*}{ Dieng et al. (1980) } & W. African & 10 & 34 & $?$ & 73.0 & 115 & RMR \\
\hline & French & 10 & 36 & $?$ & 75.0 & 111 & RMR \\
\hline \multirow[t]{4}{*}{ Hayter and Henry (1993) } & Trop 1 & 9 & 23 & 1.70 & 63.8 & 113 & RMR \\
\hline & Temp 1 & 9 & 25 & 1.76 & 67.5 & 114 & RMR \\
\hline & Trop 2 & 21 & 25 & 1.69 & 58.2 & 118 & RMR \\
\hline & Temp 2 & 20 & 23 & 1.77 & 68.3 & 114 & RMR \\
\hline
\end{tabular}

Significantly lower with ${ }^{*} P<0.05,{ }^{* \star} P<0.01$, ${ }^{* \star *} P<0.005$, by the statistical test used in the referred paper. BMR - basal metabolic rate; SMR - sleeping metabolic rate; RMR - resting metabolic rate, as specified in the cited papers, expressed in $\mathrm{kJ} \mathrm{kg}^{-1}$ per day. Trop $(1$ and 2$)=$ two groups of Tropical migrants, Temp $(1$ and 2$)=$ two groups of temperate climate residents. All references in Hayter and Henry ${ }^{46}$.

to the contrary are also published in the literature. For example a recent study on Asian women in the USA showed that BMRs measured were lower by $8.5 \%$ as compared to the FAO/WHO/UNU equations ${ }^{66}$ although no direct comparisons have been made with Caucasian Americans of the same age and sex in this study.

\section{Adaptation and energy requirements}

A working definition adopted by the FAO/WHO/UNU Expert Consultation $^{1}$ on adaptation states that it is, 'a process by which a new or different steady state is reached in response to a change or difference in the intake of food and nutrients'. This definition attempts to deal with both long-term and short-term adaptation; the word 'new' having relevance to short-term responses to changes in a subject who is in balance, i.e. acute, while the word 'different' is expected to refer to individuals or groups exposed habitually to different environmental or nutritional conditions, i.e. chronic. Three general points were made by this report in relation to both types of adaptation:

1. The concept of a 'steady state' is relative and the timescale over which a state may be considered steady or stable varies for different functions.

2. Adaptations are of different kinds - metabolic, biological/genetic, and social/behavioural.

3. It follows from the above that adaptation must imply a range of steady states and hence it is impossible to define a single point within the range that represents the 'normal'. Implicit in this is the understanding that different adapted states will bear both advantages and penalties.

The concept of a range of adapted states, each with advantages and disadvantages, while implying a respect and understanding for different biological and cultural situations, also meant that it may encourage the acceptance of double standards and the endorsement of the status quo. The Consultation was aware of this dilemma and subsequent events did reveal that the situation evolved, as the experts had feared it would.

An adaptive response is an inevitable consequence of sustained perturbation in the environment and may be genetic, physiological and/or behavioural. They are not completely separate entities as they interact with each other at several levels and are not without cost to the organism. Every adaptation has its cost and there is no such thing as a 'costless' adaptation. The processes and the costs involved may be: overt or covert, reversible or irreversible and transient or permanent. A homeostatic response in a biological system may neither have additional costs to the organism nor lead to compromise in its function, capability, or performance, in contrast to an adaptive response which may do both in order to further the survival of the individual. Adaptation, both in the shortterm and in the longterm, is a relatively slow process and should be distinguished from the rapid regulatory role of homeostatic mechanisms.

\section{Metabolic adaptation}

The suggestion that energy metabolism of individuals is more variable and adaptable and that allowances need to be made for this when arriving at estimates of human 
energy requirements has been based on several important publications that have drawn attention to the possibility of such physiological variability in energy utilisation between individuals ${ }^{67,68}$ and within individuals $^{29,30}$. Norgan ${ }^{69}$ has critically evaluated the four-fold evidences that have been adduced for this variation, which is purported to result in adaptation in human energy metabolism. These include:

1. Energy intakes can vary as much as two-fold in any group of 20 or more similar individuals ${ }^{70}$.

2. Large numbers of apparently healthy active adults exist on lower than required energy intakes ${ }^{71}$.

3. The efficiency of work and work output is variable per unit energy intake ${ }^{72}$.

4. The observations based on studies of experimental or therapeutic semi-starvation ${ }^{73-76}$ and overfeeding of humans ${ }^{77,78}$.

Differences in body size, levels of physical activity and systematic errors in the estimation of energy intakes may provide explanations for most of these observations ${ }^{69}$. However, what is implied by metabolic adaptation is that metabolic efficiency and mechanical work efficiency of the individual are variable and show an adaptation to variations in the levels of energy intake. On the basis of some observations it has been assumed that an enhanced metabolic efficiency is also a characteristic of individuals who are habitually on diets that are low in energy intakes. The implication is that their requirements for energy are lower if metabolic adaptation does occur; a feature given more than expected attention in the $\mathrm{FAO} / \mathrm{WHO} / \mathrm{UNU}$ Report of $1985^{1}$.

The naive assumption hitherto made that metabolic adaptation must occur in individuals who are habitually on low energy intakes has been explained on the basis of physiological changes that occur during experimental or therapeutic semi-starvation in previously well-nourished adults. Ferro-Luzzi ${ }^{79}$ summarised the current thinking on the ways in which an individual on habitually low intakes may metabolically adapt and respond to sustained and long-term energy imbalance. Metabolic adaptation was represented as a series of complex integration of several different processes that occurred during energy deficiency. These processes were expected to occur in phases, which could be distinguished, and a new level of equilibrium was then supposed to have been achieved at this lower plane of energy intake. At this stage, individuals who had gone through the adaptive processes that occur during longterm energy deficiency, were expected to exhibit more or less permanent sequel or costs of adaptation, which included a smaller stature and body size, an altered body composition, a lower BMR, a diminished level of physical activity and the possibility of a modified or enhanced metabolic efficiency of energy handling by the residual tissues of the body. However, a large number of measurements made over the last decade in subjects in environments that predispose to low energy intakes do not confirm the existence of an enhanced metabolic efficiency ${ }^{80}$. Other reports from rural India by McNeill, et al. $^{81}$ and by Srikantia ${ }^{82}$ confirm the results obtained by Soares and Shetty ${ }^{80}$. Results of these three studies with large sample sizes provide no evidence of metabolic adaptation in individuals from poor socio-economic groups on lower planes of energy intake. The evidence that mechanisms of improved efficiency of energy utilisation are operative in free-living populations on low energy intakes but compromised nutritional anthropometry thus appears to be tenuous and contradictory. Variations in the body composition of the chronically undernourished, more specifically the relative contributions of non-muscle and muscle mass of the residual fat free mass, may account for much of the changes seen in the BMR of the individuals ${ }^{83}$. It would then appear that an increase in metabolic efficiency in the BMR component of the energy expenditure, which has been hitherto considered to be the cornerstone of the beneficial, metabolic adaptation to long-term energy inadequacy, is of doubtful existence. This finding is probably an artefact attributable to the changes in body composition, more specifically the disproportionate reduction in muscle tissue with a normal or even increased non-muscle or visceral organ size possibly contributed to by the increase in number of infective episodes in these individuals that occur in these environments. Hence it is highly unlikely that metabolic adaptation is of any relevance in this state as opposed to a situation where normal individuals are energy restricted. Hence it is only appropriate that metabolic adaptation be denied any role in influencing the estimation of energy requirements of adults particularly in the developing world.

\section{Behavioural adaptation}

Behavioural adaptation in physical activity patterns that accompany low energy intake states are related to the individual's allocation of time and energy to different productive and leisure activities and to the biological as well as the economic consequences of these altered behavioural patterns. When there is both a fall in energy intakes and an increased demand for energy expenditure at work, for instance during seasonal agricultural activities, individuals adjust the time they allocate to different tasks; more time is given to work activities and less time and energy to productive tasks at home or socially desirable or pleasurable activities ${ }^{84}$. A marked reduction in food intake has been shown to lead to a profound decrease in physical activity $^{85}$. An analysis of physical activity patterns during voluntary reduction in food intake has shown that the behavioural response to a deficient intake is a change in the pattern of activity ${ }^{86}$. The loss in body weight associated 
with the deficient intake was associated with a marked change in activity patterns; lower effort discretionary activities replaced by those which needed greater effort while obligatory activities were not affected. Rural Guatemalan men were able to carry out the specific agricultural task allocated to them, but took a longer time doing it $^{87}$; these individuals, however, took a longer time to walk home and spent nearly 3 hours resting or taking a nap or indulging in very sedentary activities during the rest of the day. Rural women in India and Africa on marginal energy intakes and low body mass index (BMI) have been shown to spend fewer hours working per day and more time resting than better-off individuals in the same socioeconomic milieu ${ }^{88,89}$. There are reports that show appreciable increases in both activity at work and in discretionary activities without concurrent changes in body weight, in male agricultural workers whose diet was supplemented $^{90}$. There was also an improvement in their sense of well-being. Similar improvements in subjective well-being with very small body weight increases have been seen in lactating Gambian women when provided supplementary food ${ }^{91}$. These carefully analysed studies support the existence of behavioural adaptation in the spontaneous, free-living physical activity of adults which may limit their work output, economic productivity and income-generating ability, at the same time restricting their socially desirable and discretionary or even their obligatory physical activity. This latter behavioural adaptation becomes an important survival strategy. The consequences of low energy intakes and the adaptations that may occur and their implications for not merely the assessment of energy requirements, but also for good health and survival have been recently reviewed in $\operatorname{detai1}^{92,93}$. Recommendations for energy requirements have to take into consideration the energy needs to cope with the downside of functional consequences and behavioural adaptation in adults.

\section{TEE and PAL in adults}

The recommendation by the $1985 \mathrm{FAO} / \mathrm{WHO} / \mathrm{UNU}$ Expert Consultation Report ${ }^{1}$ that energy requirements be based on the assessment of energy expenditure rather than energy intake posed a huge problem because of the difficulties associated with measuring the contribution of physical activity, the most variable component of TEE. A major breakthrough was the application of the DLW method to humans under free-living conditions; a method developed in the early 1950 s by Lifson and McClintock ${ }^{94}$. During the first 10 years of its use in humans the DLW method was extensively validated ${ }^{95}$ and is now considered to be the gold standard for the measurement of TEE. Its application among other contributions to nutrition has advanced our understanding of the energy requirements in health and various disease states throughout the lifecycle, from new-born infants to the very elderly.

\section{DLW data}

The DLW technique of measuring TEE permits determination of free-living energy expenditure integrated over a period of days, usually between 7 and 20 days. The first data from humans was published in 1982 ${ }^{96}$. Between 1982 and 1994 sufficient data accumulated to form the basis for establishing energy requirements. A database of 1614 DLW measurements in 1156 individuals (aged 2-90 years) was collated and comprehensively analysed in $1995^{34}$. The main analysis was made in a subset of 574 subjects in whom (i) both TEEs by DLW and BMR measurements were available, (ii) under normal free-living conditions and (iii) from subjects from affluent societies in the developed world. Details of the methodologies employed, the database, studies included and excluded, and full references can be found in their paper. Three years after this compilation it was estimated that the number of subjects on whom DLW measurements were available had tripled $^{97}$ and it appeared that much of the data seemed to support the conclusions drawn by Black and her colleagues $^{34}$. It is hoped that the Expert Consultation for whose consideration this background document is being produced will benefit from the meta-analysis of all available data on DLW from the developed and industrialised world being compiled by the Institute of Medicine (IOM).

The number of studies carried out using the DLW technique in the developing world are limited. The review by Coward $^{98}$ provided an analysis of data from 12 published papers. Since then there have been a few publications from the developing world ${ }^{99,100}$. These two studies address the issues that were raised particularly with regard to DLW data from well-nourished individuals in the developing world since much of the data is based on measurements made on relatively poor labouring classes in the developing world ${ }^{98}$. In general the conclusions that can be made are that the current estimates of energy requirements based on other measures look about right. There is also some suggestion that perhaps the requirements of physically active people must be higher implying that the PAL values attributed to the heavy activity levels may have to be revised upwards. Where comparisons have been made it appears that well-nourished individuals expend much more energy than poorly nourished (or chronically energy deficient, low BMI individuals) in urban settings ${ }^{100}$. This may be at the cost of socially desirable levels of activity since the same study found that undernourished individuals in rural agricultural societies sustain high levels of expenditure like the well nourished despite having low body weights and BMIs. This fact is also borne by Coward's analysis ${ }^{98}$ of much of the DLW data from the developing world. It is quite evident that more data needs to be generated in a systematic way from the developing world if DLW estimates of TEE are suggested as an alternative to replace or complement the PAL system of arriving at energy requirements of adults. 


\section{Usage, validity and variability of PAL index}

TEE is expressed as multiples of the BMR to express the requirements of adults as previously recommended by the last $\mathrm{FAO} / \mathrm{WHO} / \mathrm{UNU}$ Expert Consultation Report ${ }^{1}$ on Energy and Protein requirements. The latter is referred to as the PAL and calculated by the expression TEE/BMR. The expression of energy expenditure (or requirements) of adults as PAL i.e. as multiples of BMR provides a convenient way of controlling for age, sex, body weight and body composition and for expressing the energy needs of a wide range of people in a shorthand form. The figures derived by the 1985 Consultation were based on theoretical factorial calculations making assumptions about energy cost and the duration of day-to-day activities. The data in Table 8 on PAL values in adults is derived from actual measurements using DLW technique. PAL provides a useful means of categorising energy requirements in a single number, taking into account differences in body size as represented by BMR. However, the value of PAL depends both on BMR and TEE, and both have errors of measurement, so that PAL is only imprecisely estimated. The CV of BMRs when actually measured is very small as earlier described, while the CV of BMRs predicted using the Schofield equations for given body weight is of the order of about $8 \%{ }^{42}$. For TEE, the within-subject CV can be obtained from studies with repeated DLW measurements where weight, activity and physiological state have been controlled for and remained the same. Data from nine such studies collated by Black, et al. ${ }^{34}$ have shown that the mean within-individual CV for 79 subjects was $8.9 \%$ and this includes methodological error as well as variations in activity levels. Thus, the 95\% confidence limits on PAL at the individual level, assuming a measured BMR and no change in body weight or PAL, is of the order of $\pm 18.5 \%$ representing about \pm 0.3 PAL units on a mean PAL value of 1.65 .

Table 8 also presents TEE, BMR, and energy expenditure for activity (AEE) derived as TEE minus BMR. The latter expression has hitherto not been used although a related expression i.e. physical activity ratio (PAR) has been in vogue. PAR is used as an abbreviation for the multiple of BMR for an activity and is used to provide an energy cost for a specific activity such as sitting down, walking, etc. On the other hand, AEE represents the energy expended by an individual over and above the BMR including dietary induced thermogenesis (DIT) and for physical activity. The usage of PAL treats it as an index of TEE adjusted for BMR. Black et al. ${ }^{34}$ have shown by rigorous systematic regression analysis that both weight and height are positive predictors of all components of TEE except when TEE is expressed as a PAL value when the weight effect disappears.

\section{The limits of human energy expenditure}

Studies carried out under unusual special conditions provide information on energy expenditure at the extremes of PAL in adults and thus provides a frame of reference for evaluating results of TEE and PAL from the general population. These studies of TEE measurements using the DLW technique have been summarised by Black et $a l .{ }^{34}$. At the lower limit of physical activity studies in non-ambulatory chair-bound subjects and in individuals confined to a calorimeter and apparently not exercising provide a mean PAL of 1.21. This is slightly lower than the value of 1.27 suggested by $\mathrm{FAO} / \mathrm{WHO} / \mathrm{UNU}^{1}$, as the survival requirement. At the upper limit of physical activity there is a distinction to be drawn between the maximum achievable over a limited period of time and the maximum sustainable as a long-term way of life given physical fitness and adequate food. The maximum achieved over limited periods of time was a PAL of $>4.0$ and TEE of $33 \mathrm{MJ} \mathrm{day}^{-1}$ in the Tour de France and in polar exploration. The maximum for a sustainable way of life may be that represented by soldiers on active service with a mean PAL of 2.4 and TEE of $18 \mathrm{MJ} \mathrm{day}^{-1}$. In support of this energy intakes of $19.5 \mathrm{MJ} \mathrm{day}^{-1}$ have been recorded in colliers in 1923 (Moss, 1923) and in lumberjacks in $1959^{101}$. Among athletes in training, mean PAL of 2-3.5 were found with TEE ranging from 11 to $18 \mathrm{MJ} \mathrm{day}^{-1}$ in women, and from 15 to $30 \mathrm{MJday}^{-1}$ in men. PAL greater than 2.4 were

Table 8 Subject characteristics and energy expenditure in different age and sex groups

\begin{tabular}{|c|c|c|c|c|c|c|c|c|c|c|c|c|c|c|c|c|c|}
\hline \multirow[b]{2}{*}{ Age group (y) } & \multirow[b]{2}{*}{$n$} & \multicolumn{2}{|c|}{ Age (y) } & \multicolumn{2}{|c|}{$\begin{array}{l}\text { Height } \\
(\mathrm{m})\end{array}$} & \multicolumn{2}{|c|}{$\begin{array}{l}\text { Weight } \\
(\mathrm{kg})\end{array}$} & \multicolumn{2}{|c|}{$\begin{array}{c}\mathrm{BMI} \\
\left(\mathrm{kg} \mathrm{m}^{-2}\right)\end{array}$} & \multicolumn{2}{|c|}{$\begin{array}{c}\text { TEE } \\
\left(\mathrm{MJ} \mathrm{day}^{-1}\right)\end{array}$} & \multicolumn{2}{|c|}{$\begin{array}{c}\text { BMR } \\
\left(\mathrm{MJ} \mathrm{day}^{-1}\right)\end{array}$} & \multicolumn{2}{|c|}{$\begin{array}{c}\mathrm{AEE} \\
\left(\mathrm{MJ} \mathrm{day}^{-1}\right)\end{array}$} & \multicolumn{2}{|c|}{ PAL } \\
\hline & & Mean & SD & Mean & SD & Mean & SD & Mean & SD & Mean & SD & Mean & SD & Mean & SD & Mean & SD \\
\hline \multicolumn{18}{|l|}{ Females } \\
\hline $18-29$ & 89 & 24.4 & 3.7 & 1.66 & 0.06 & 69.2 & 22.3 & 25.3 & 8.1 & 10.4 & 2.2 & 6.2 & 1.1 & 4.2 & 1.7 & 1.70 & 0.28 \\
\hline $30-39$ & 76 & 33.8 & 3.0 & 1.64 & 0.07 & 67.9 & 13.9 & 25.2 & 4.9 & 10.0 & 1.7 & 6.0 & 0.6 & 4.1 & 1.5 & 1.68 & 0.25 \\
\hline $40-64$ & 47 & 51.6 & 8.3 & 1.65 & 0.07 & 70.0 & 13.3 & 25.9 & 4.6 & 9.8 & 1.7 & 5.8 & 0.7 & 4.0 & 1.4 & 1.69 & 0.23 \\
\hline \multicolumn{18}{|l|}{ Males } \\
\hline $18-29$ & 56 & 22.5 & 3.5 & 1.77 & 0.07 & 75.6 & 18.4 & 24.0 & 5.3 & 13.8 & 3.0 & 7.5 & 1.2 & 6.3 & 2.5 & 1.85 & 0.33 \\
\hline $30-39$ & 36 & 34.3 & 3.3 & 1.79 & 0.06 & 86.1 & 31.4 & 26.8 & 8.8 & 14.3 & 3.1 & 8.2 & 1.8 & 6.1 & 2.5 & 1.77 & 0.31 \\
\hline $40-64$ & 15 & 50.6 & 8.8 & 1.76 & 0.06 & 77.0 & 10.0 & 24.9 & 3.0 & 11.5 & 1.7 & 7.0 & 0.8 & 4.5 & 1.3 & 1.64 & 0.17 \\
\hline
\end{tabular}

Source: Black et al. ${ }^{34}$. BMI - body mass index; TEE - total energy expenditure; BMR - basal metabolic rate; AEE - energy expenditure for activity; PAL physical activity levels. 
obtained during periods of 'rigorous training', which is unlikely to be a sustained lifestyle. The lower values for PAL, 2.0-2.3 were obtained in periods of apparently routine training and may well be sustained for extended periods of time. Similar values have been observed in Gambian women during the farming season ${ }^{102}$. These data suggest a PAL range of 1.2-2.5 for sustainable lifestyles, where 1.2 is indicative of a non-ambulant life style and 2.5 represents a very physically active lifestyle (Table 9).

\section{Energy expenditure of free-living adults with normally active daily life}

A total of 319 adults (212 non-pregnant non-lactating (NPNL) females and 107 males aged 18-64 years were identified as healthy, free-living, following normal daily life, not recruited as having specific and special circumstances, occupations or activities, and in whom BMR had been measured. Table 8 summarises the anthropometric characteristics of the sample by age and sex. Table 8 also shows the data for TEE, BMR, AEE and PAL by age and by sex. The data fully encompassed the PAL range 1.2-2.5 established above as the likely range of sustainable energy expenditures (Table 9). The wide range of expenditures at any age was notable. Regression analysis of the entire data set accumulated by Black et al. ${ }^{34}$ which included a total data set of 574 subjects aged 2-90 years on whom DLW data and BMR measurements were available, indicated that equations based on weight, height, age and sex can explain $77 \%$ and $86 \%$ of the variance in TEE and BMR, and $41 \%$ of the variance in AEE. The latter i.e. AEE was found to be much more sensitive to individual behavioural choices and therefore less definable using purely physiological measures. As anticipated, both weight and height were positive predictors of all components of energy expenditure, except when TEE was expressed as PAL when the weight effect disappeared. Age was a negative predictor of energy expenditure, particularly of the activity component (AEE). Age remained a negative predictor when TEE was expressed as PAL. It appeared from this rigorous analysis of Black and her colleagues $^{34}$ that females tend to expend about $11 \%$ less

Table 9 PAL based on DLW studies

\begin{tabular}{lc}
\hline Lifestyle and level of activity & $\mathrm{PAL}$ \\
\hline Chair-bound/bed-bound & 1.2 \\
$\begin{array}{l}\text { Seated work with no option of moving around and } \\
\quad \text { little or no strenuous leisure activity }\end{array}$ & $1.4-1.5$ \\
$\begin{array}{l}\text { Seated work with discretion and requirement } \\
\quad \text { to move around but little or no strenuous }\end{array}$ & $1.6-1.7$ \\
$\quad$ leisure activity & \\
Standing work (e.g. housework, shop assistant) & $1.8-1.9$ \\
$\quad \begin{array}{l}\text { Significant amounts of sport or strenuous leisure } \\
\quad \text { activity (30-60 minutes 4-5 times per week) }\end{array}$ & +0.3 \\
Strenuous work or highly active leisure time & $2.0-2.4$ \\
\hline
\end{tabular}

Source: Black et al. ${ }^{34}$. PAL - physical activity levels; DLW - doubly labelled water. energy than males after adjustment for body size. Taken together with the regression analysis the following key features seem to emerge from the analysis of Black et al. ${ }^{34}$ :

- In early life absolute levels of energy expenditure whether expressed as TEE, BMR or AEE rise with increasing body size, peak in the young adult years and decline thereafter. Adjusted for body size, TEE declines with age throughout life.

- Adjusted for body size, males have $11 \%$ greater TEE than females.

- Expressed as PAL, differences with age remain significant. For females PAL is fairly constant during the adult years and lower at younger and older ages. For males PAL rises to a peak at 18-29 years and declines thereafter.

- Differences in expenditure between the sexes are not completely removed by adjusting for body size using PAL, although the sex effect is confounded with height to some extent.

- As expected, mean TEE in the free-living population, however expressed, is well below that of the athletes in training and soldiers on exercises. It is important to note that this sample of 319 adults was from affluent societies and contains very few manual workers with no data from physically active individuals in developing countries.

The review by Black and colleagues ${ }^{34}$ may not have had the benefit of a separate meta-analysis by Carpenter and colleagues $^{103}$ looking at the influence of body composition and RMR on the variation in TEE measured by DLW. This analysis was based on data from 13 studies in a total of 162 adults. The review concluded that the relationships between TEE and RMR are highly variable; that after adjustment of TEE for RMR, TEE is not associated with adiposity; and that women have a significantly lower TEE than men do. Some of these findings lend support to the analysis of Black and colleagues ${ }^{34}$.

\section{PAL from DLW data on free-living adults in developed societies}

An examination of the distribution of the energy expenditure of adults aged 18-64 years ${ }^{50}$ shows that the distributions of PAL for both men and women have a modal value at 1.6 (encompassing 1.55-1.65). The distribution for men has a shoulder to the right suggesting the existence of two populations - active and inactive. This could be either real or an artefact of the sample. Many of the authors gave no information about the subjects beyond sex, age and body weight. Subjects designated as free-living were typically recruited from among colleagues, from employees in research centres, universities or hospitals, or were volunteers responding to advertising in the local media. Occupations were typically student, housewife, white collar or professional 
occupation, unemployed or retired. Only three individuals were specifically identified as manual workers. This suggests a predominantly 'sedentary' population. However, some individuals had PAL levels associated with athletes or soldiers in training and the limited information on occupation or activity usually suggested plausible reasons for these high values. Among the 20 highest values were three manual workers, six out of 13 'university students and laboratory technicians' with an average of 34 minutes 'strenuous activity' per day and with several active sports specifically mentioned, while five 18-year-old college students and two professionals were known to cycle or walk as a primary means of transport. Women were not well represented in data set at the higher PAL levels. Whether this reflects an absence of subjects recruited from more active groups or a general tendency for women to be less involved in strenuous activities is not known.

Western lifestyle is commonly referred to as 'sedentary', and the recommendation of $\mathrm{FAO} / \mathrm{WHO} / \mathrm{UNU}^{1}$ for light activity $(1.55 \times \mathrm{BMR})$ is frequently interpreted as 'sedentary' and taken as applying to the generality of the population. However, many desk jobs involve frequent moving around. Other occupations, not necessarily strenuous, require the person to be on their feet all day (e.g. housewives, shop assistants, nurses, and storekeepers). Thus a PAL of 1.55-1.65 appears to represent the average for the so-called sedentary lifestyle. There are also data to suggest that activities do not have to be obviously strenuous for relatively high PAL values to be achieved. Calorimetry studies allowing 'free activity' provide mean PAL ranging from 1.50 to 1.75 and individual PAL from 1.39 to 2.04. A factorial calculation based on 8 hours sleep (PAL 0.95), 4 hours sitting (PAL 1.2) and 12 hours walking around (PAL 2.5) might represent the lifestyle of a housewife and yields a PAL of $1.8 \times$ BMR.

A PAL of 1.35 has been suggested as the lowest PAL compatible with long-term weight maintenance in persons other than the completely chair or bed-bound; this was the mean PAL in nine calorimeter studies $(n=207)$ with controlled limited activity ${ }^{104}$. The distribution of energy expenditure of adults referred to earlier ${ }^{50}$ shows that $7.5 \%$ of men and $10.9 \%$ of women have a PAL below 1.35; although these may not be representative of their true long-term energy expenditures due to imprecision of the methods. The CV on repeat DLW measurements was $8.9 \%$ from nine studies $(n=79)$ on subjects with no change in activity, weight or physiological status, and while the $\mathrm{CV}$ on measured BMR can be as low as $2.5 \%$ under the rigorously controlled conditions of a calorimeter, many studies employed less rigorous conditions. The combined error for PAL is at least equal to $\pm 9.2 \%$; while the FAO/WHO/UNU Report of $1985^{1}$ suggested that the inter-individual variability in TEE in a specified group of individuals in whom energy expenditure measurements have been made over a week has a CV of $\pm 12.5 \%$ on a body weight basis ${ }^{105}$.

The effect of moderate sport on energy expenditure can be gauged from three studies $(n=28)$ that imposed a programme of exercise on free-living people normally undertaking very little strenuous activity. The mean sedentary and exercising PAL were 1.63 (SD 0.16) and 1.99 (SD 0.19), respectively. The mean sedentary and exercising TEEs were 10.53 MJ (SD 1.67) and 12.54 MJ (SD $2.14)$, respectively. These figures lend support to the mode of 1.6 for 'sedentary' lifestyles, and show that 30-60 minutes of active sport 4-5 times per week can raise PAL by 0.3 units, but need not necessarily be reflected in a PAL above 2.0.

The relationship between lifestyle, activity and PAL was suggested by a careful analysis of the available data based on DLW studies in adults in developed countries are summarised by Black et $a l .{ }^{34}$. The data provides little evidence to quantify the energy cost of or to make PAL recommendations for manual occupations with fairly strenuous PAL that are occupation related. The range of PAL values, which are considered as the maximum for a sustainable lifestyle, appears to be between 2.0 and 2.4. The higher energy expenditures seen in adults in the analysis by Black et al. ${ }^{34}$ appear to be due to recourse to active means of transportation such as that resulting from cycling or walking, or due to regular participation in active sports. This emphasises the importance of sport or active leisure pursuits in raising energy expenditure in sedentary Western populations, which may provide both for socially desirable activities, as well as providing for activities for physical fitness and the promotion of health in these lifestyle situations.

\section{Concluding comments}

The Joint FAO/WHO/UNU Expert Committee on Energy and Protein Requirements ${ }^{1}$ suggested the average daily energy requirement of adults whose occupational work is classified as light, moderate, or heavy, expressed as a multiple of BMR, to be as follows:

$\begin{array}{lccc} & \text { Light } & \text { Moderate } & \text { Heavy } \\ \text { Men } & 1.55 & 1.78 & 2.10 \\ \text { Women } & 1.56 & 1.64 & 1.82\end{array}$

It is obviously difficult to relate these categories to the data in the analysis of DLW studies ${ }^{34}$ as the information on occupations was limited and the categories do not take active leisure into account. The modal value of 1.55-1.65 for adults in the analysis falls between the light and moderate categories. The suggested range for strenuous occupation of $2.0-2.4$ is compatible with the recommendation of 2.10 for heavy occupations. The DLW data on adults do not suggest that these recommendations made by the Expert Consultation prior to the availability of this new technology that provides for estimates of TEE in free-living adults are 
seriously at departure from the more recent estimates using this novel technique.

A suggestion is being made that once the available data on DLW throughout the world is compiled and then subjected to meta-analysis by the IOM, this would form a valuable resource to potentially look in more creative ways at the levels of activity based on actual measurements in free-living individuals whose habitual expenditure have been measured by this novel and noninvasive method. They could then be categorised into tertiles to represent the three levels of activities that are currently recommended by the factorial approach. Whether the mean/median and the confidence intervals would be used is not clear. However the major limitation of this approach is the fact that the data from the developing world (who represent the bulk of humanity in the world) is very limited and forms a very small proportion of the whole database and questions the representative nature of the categories that are being derived. The merits of this approach for a FAO/WHO/UNU Expert Consultation are clearly debatable although the experts should have the option to consider this view. It would, however be, a retrograde step if the currently used PAL system was abandoned and replaced by a new approach. At best this new approach should be used to complement the categorisation based on the PAL method.

\section{Acknowledgements}

This document has heavily drawn on and is an update of an International Dietary Energy Consultancy Group (IDECG) paper presented at the workshop on energy and protein requirements subsequently published in a supplement of the European Journal of Clinical Nutrition ${ }^{50}$.

\section{References}

$1 \mathrm{FAO} / \mathrm{WHO} / \mathrm{UNU}$ Expert Consultation. Energy and protein requirements. WHO Technical Report Series 724: 1-206. Geneva: World Health Organization, 1985.

2 Segal KR. Comparison of indirect calorimetric measurements of resting energy expenditure with a ventilated hood, face mask and mouthpiece. American Journal of Clinical Nutrition 1987; 45: 1420-3.

3 Soares MJ, Sheela ML, Kurpad AV, Kulkarni RN, Shetty PS. The influence of different methods on basal metabolic rate measurements in humans. Human Nutrition: Clinical Nutrition 1989; 50: 731-6.

4 Clark HD, Hoffer LF. Reappraisal of the resting metabolic rate of normal young men. American Journal of Clinical Nutrition 1991; 53: 21-6.

5 Shetty PS, Soares MJ, Sheela ML. Basal metabolic rates of South Indian males. Rome: Report to FAO, 1986.

6 Garlick PJ, McNurlan MA, McHardy KC, Calder AG, Milne E, Fearns LM, Broom J. Rates of nutrient utilisation in man measures by combined respiratory gas analysis and stable isotope labelling: effect of food intake. Human Nutrition: Clinical Nutrition 1987; 41C: 177-91.
7 Brockway JM. Derivation of formulae used to calculate energy expenditure in man. Human Nutrition: Clinical Nutrition 1987; 41C: 463-72.

8 Weir JB. New method for calculating metabolic rate with special reference to protein metabolism. Journal of Physiology 1949; 109: 1-9.

9 Consolazio CF, Johnson RE, Pecora E. Physiological methods of metabolic functions in man. New York: McGraw Hill, 1963, 313-7.

10 Brouwer E. Report of subcommittee on constants and factors. In: KL Blaxter, ed. Third Symposium on energy metabolism, European Association for Animal Production. No. II. London Academic Press, 1965: 441-3.

11 Passmore R, Eastwood MA. In: Davidson and Passmore: Human nutrition and dietetics, 8th ed. Edinburgh: Churchill Livingstone, 1986, 18-9.

12 McLean JA. Heat production or oxygen consumption? In: Van Es AJH, ed. Human energy metabolism. Euro-nut report no. 5. Netherlands: Wageningen, 1984, 187-9.

13 Westerterp KR. Alterations in energy balance with exercise. American Journal of Clinical Nutrition 1998; 68: S970-S4.

14 Schulz LO, Nyomba BL, Alger S, Anderson TE, Ravussin E. Effect of endurance training on sedentary energy expenditure measured in a respiratory chamber. American Journal of Physiology 1991; 260E: 257-61.

15 Sjodin AM, Forslund AH, Westerterp KR, Anderson AB, Forslund JM, Hambraeus LM. The influence of physical activity on BMR. Medical Science in Sports and Exercise 1996; 28: 85-91.

16 Meijer GA, Westertrep KR, Seyts GH, Janssen GM, Saris WH, Ten Hoor F. Body composition and sleeping metabolic rate in response to a 5-month endurance-training programme in adults. European Journal of Applied Physiology and Occupational Physiology 1991; 62: 18-21.

17 Broeder CE, Burrhus KA, Svanevik LS, Wilmore JH. The effects of either high intensity resistance or endurance training on resting metabolic rate. American Journal of Clinical Nutrition 1992; 55: 802-10.

18 Westerterp KR, Meijer GA, Schoffelen P, Janssen EM. Body mass, body composition and sleeping metabolic rate before, during and after endurance training. European Journal of Applied Physiology and Occupational Physiology 1994; 69: 203-8.

19 Wilmore JH, Stanforth PR, Hudspeth LA, Gagnon J, Daw EW, Leon AS, Rao DC, Skinner JS, Bouchard C. Alterations in resting metabolic rate as a consequence of 20 weeks of endurance training: the HERITAGE Family Study. American Journal of Clinical Nutrition 1998; 68: 66-71.

20 Westerterp KR, Goran MI. Relationship between physical activity related energy expenditure and body composition: a gender difference. International Journal of Obesity and Related Metabolic Disorders 1997; 21: 184-8.

21 Edholm OG. Energy expenditure and calorie intake in young men. Proceedings of the Nutrition Society 1961; 20: 71-6.

22 Garby L, Lammert O, Nielsen E. Within subjects, between weeks variation in $24 \mathrm{~h}$ energy expenditure for fixed physical activity. Human Nutrition: Clinical Nutrition 1984; 38C: 391-4.

23 De Boer JO. Energy requirements of lean and obese women, assessed by indirect calorimetry. $\mathrm{PhD}$ Thesis, Agricultural University: Wageningen, Netherlands, 1985.

24 Jequier E, Schutz Y. The contribution of BMR and physical activity to energy expenditure. In: Cioffi LA, James WPT, Van Itallie TB, eds. Body weight regulatory system: normal and disturbed mechanisms. New York: Raven Press, 1981, 89-96.

25 Schutz Y. Terminology, factors and constants in studies on energy metabolism of humans. In: van Es AJH, ed. Human energy metabolism. EURO-NUT Report No. 5. Netherlands: Wageningen, 1984, 153-68. 
26 Daly JM, Heymsfield SB, Head CA, Harvey LP, Nixon DW, Katzeff H, Grossman GD. Human energy requirements: overestimation by widely-used prediction equation. American Journal of Clinical Nutrition 1985; 42: 1170-4.

27 Dallosso HM, James WPT. The effect of fat over-feeding on 24 h energy expenditure. British Journal of Nutrition 1984; 52: $49-64$.

28 Dallosso HM, Murgatroyd PR, James WPT. Feeding frequency and energy balance in adult males. Human Nutrition: Clinical Nutrition 1982; 36C: 25-39.

29 Sukhatme PV, Margen S. Auto-regulatory homeostatic nature of energy balance. American Journal of Clinical Nutrition 1982; 35: 355-65.

30 Sukhatme PV, Narain P. Intra-individual variation in energy requirements and its implication. Indian Journal of Medical Research 1983; 78: 857-65.

31 Soares MJ, Shetty PS. Intra-individual variations in resting metabolic rates of human subjects. Human Nutrition: Clinical Nutrition 1986; 40C: 365-9.

32 Webb P, Abrams T. Loss of fat stores and reduction in sedentary energy expenditure from undereating. Human Nutrition: Clinical Nutrition 1983; 37C: 271-82.

33 Webb P, Annis JF. Adaptation to overeating in lean and overweight men and women. Human Nutrition: Clinical Nutrition 1983; 37C: 117-31.

34 Black AE, Coward WA, Cole TJ, Prentice AM. Human energy expenditure in affluent societies: analysis of 574 doubly-labelled water measurements. European Journal of Clinical Nutrition 1996; 50: 72-92.

35 Shetty PS, Soares MJ. Variability in basal metabolic rates of man. In: Blaxter K, MacDonald I, eds. Comparative nutrition. London: John Libbey, 1988, 141-8.

36 Henry CJK, Hayter J, Rees DG. The constancy of basal metabolic rate in free-living male subjects. European Journal of Clinical Nutrition 1989; 43: 727-31.

37 Lammert O, Garby L, Maron K, Mork G, Thein M, FlindtEgebak P, Krogh-Hansen J. Effect of the preceding days energy intake on the energy cost of rest, arm and leg exercise. Human Nutrition: Clinical Nutrition 1987; 41C: 141-7.

38 Soares MJ, Shetty PS. Long term stability of metabolic rates in young adult males. Human Nutrition: Clinical Nutrition 1987; 41C: 287-90.

39 Aub JC, Du Bois EF. The basal metabolism of old men. Archives of Internal Medicine 1917; 19: 823-34.

40 Robertson JD, Reid DD. Standards for basal metabolism of normal people in Britain. Lancet 1952; 1: 940-3.

41 Quenouille MH, Boyne AW, Fisher WB, Leitch I. Statistical studies of recorded energy expenditure of man. Part I. Basal metabolism related to sex, stature, age, climate and race. Commonwealth Bureau of Animal Nutrition Technical Communication No. 17. Aberdeen: Commonwealth Agricultural Bureau, 1951.

42 Schofield WN. Predicting basal metabolic rate, new standards and review of previous work. Human Nutrition: Clinical Nutrition 1985; 39C: 5-91.

43 Henry CJK, Rees DG. New prediction equations for the estimation of basal metabolic rate in tropical peoples. European Journal of Clinical Nutrition 1991; 45: 177-85.

44 Piers LS, Shetty PS. Basal metabolic rates of Indian women. European Journal of Clinical Nutrition 1993; 47: 586-91.

45 Soares MJ, Francis DG, Shetty PS. Predictive equations for basal metabolic rates of Indian males. European Journal of Clinical Nutrition 1993; 47: 389-94.

46 Hayter JE, Henry CJK. Basal metabolic rate in human subjects migrating between tropical and temperate regions a longitudinal study and review of previous work. European Journal of Clinical Nutrition 1993; 47: 724-34.

47 Henry CJK, Piggott SM, Emery B. Basal metabolic rate and dietary thermogenesis in Asians living in Britain. Human Nutrition: Clinical Nutrition 1987; 41C: 397-402.
48 Hayter JE. The variability of energy expenditure in populations of different geographic origins. PhD Thesis, Oxford Brookes University, 1992.

49 Valencia ME, Moya SY, McNeill G, Marcus R. Basal metabolic rate and body fatness of adult men in Northern Mexico. European Journal of Clinical Nutrition 1994; 48 205-11.

50 Shetty PS, Henry CJK, Black AE, Prentice AM. Energy requirements of adults: an update on basal metabolic rates (BMRs) and physical activity levels (PAL). European Journal of Clinical Nutrition 1996; 50S: 11-23.

51 Piers LS, Diffey B, Soares MJ, Frandsen SL, McCormack LM, Lutschini MJ, O'Dea K. The validity of predicting the basal metabolic rate of young Australian men and women. European Journal of Clinical Nutrition 1997; 51: $333-7$.

52 Soares MJ, Piers LS, O'Dea K, Shetty PS. No evidence for an ethnic influence on basal metabolism: an examination of data from India and Australia. British Journal of Nutrition 1999; 81: 81-2.

53 Nelson KM, Weinsier RL, Long CL, Schutz Y. Prediction of resting energy expenditure from fat-free mass and fat mass. American Journal of Clinical Nutrition 1992; 56: 848-56.

54 Weinsier RL, Shutz Y, Bracco D. Re-examination of the relationship of resting metabolic rate to fat-free mass and to the metabolically active components of fat free mass of humans. American Journal of Clinical Nutrition 1992; 55 $1790-4$.

55 Schofield WN, Schofield C, James WPT. Basal metabolic rate-review and prediction, together with an annotated bibliography of source material. Human Nutrition: Clinical Nutrition 1985; 39C: 5-91.

56 Mukerjee HN, Gupta PC. The basal metabolism of Indians (Bengalis). Indian Journal of Medical Research 1931; 11: 807-11.

57 Krishnan BT, Vareed C. Basal metabolism of young college students, men and women in Madras. Indian Journal of Medical Research 1932; 12: 831-58.

58 Henry CJK, Rees DG. A preliminary analysis of basal metabolic rate and race. In: Blaxter K, Macdonald I, eds. Comparitive nutrition. London: John Libbey, 1988, 149-59.

59 Liu HY, Lu YF, Chen WJ. Predictive equations for basal metabolic rate in Chinese adults: a cross validation study. Journal of the American Dietetic Association 1995; 95 $1403-8$.

60 Leung R, Woo J, Chan D, Tang N. Validation of prediction equations for basal metabolic rate in Chinese subjects. European Journal of Clinical Nutrition 2000; 54: 551-4.

61 Rush EC, Plank LD, Coward WA. Energy expenditure of young Polynesian and European women in New Zealand and relations to body composition. American Journal of Clinical Nutrition 1999; 69: 43-8.

62 Carpenter WH, Fonong T, Toth MJ, Ades PA, CallesEscandon J, Walston JD, Poehlman ET. Total daily energy expenditure in free living older African-Americans and caucasians. American Journal of Physiology 1998; 274E 96-101.

63 Sable AD, Fontvielle AM, Harper IT, Ravussin E. Low levels of physical activity in 5 year old children. Journal of Paediatrics 1997; 131: 423-9.

64 Sun M, Gower BA, Nagy TR, Trowbridge CA, Dezenberg C, Goran MI. Total, resting and activity related energy expenditures are similar in Caucasian and African-American children. American Journal of Physiology 1998; 274E: $232-7$.

65 Wong WW, Butte NF, Ellis KJ, Hergenroeder AC, Hill RB, Stuff JE, Smith EO. Pubertal African-American girls expend less energy at rest and during physical activity than Caucasian girls. Journal of Endocrinology and Metabolism 1999; 84: 906-11. 
66 Case KO, Brahler CJ, Heiss C. Resting energy expenditures in Asian women measured by indirect calorimetry are lower than expenditures calculated from prediction equations. Journal of the American Dietetic Association 1997; 97: 1288-92.

67 Durin JVGA, Edholm OG, Miller DS, Waterlow JC. How much food does man require? Nature 1973; 242: 418.

68 Edmundson W. Adaptation to undernutrition: how much food does man need? Social Science and Medicine 1980; 14D: $19-126$

69 Norgan NG. Adaptation of energy metabolism to level of energy intake. In: Parizkova J, ed. Energy expenditure under field conditions. Prague: Charles University, 1983, 56-64.

70 Widdowson EM. Nutritional individuality. Proceedings of the Nutrition Society 1962; 21: 121-8.

71 Durnin JVGA. Energy balance in man with particular reference to low energy intakes. Bibliotheca Nutritio et Dietata 1979; 27: 1-10.

72 Edmundson W. Individual variations in basal metabolic rate and mechanical work efficiency in East Java. Ecology of Food and Nutrition 1979; 8: 189-95.

73 Benedict FG, Miles WR, Roth P, Smith HM. Human vitality and efficiency under prolonged restricted diet. Carnegie Institute of Washington, DC: Carnegie Institute of Washington Publication No. 280, 1919.

74 Keys A, Brozeck J, Henschel A, Mickelson O, Taylor HL. The biology of buman starvation. Minneapolis: University of Minneapolis Press, 1950.

75 Grande F. Man under caloric deficiency In: Handbook of Physiology, Adaptation to the Environment. American Physiological Society, Washington, 1964: 911-37.

76 Apfelbaum M. Adaptation to changes in caloric intake. Progress in Food and Nutrition Science 1978; 2: 543-59.

77 Sims EAH. Experimental obesity, dietary induced thermogenesis and their clinical implications. Clinics in Endocrinology and Metabolism 1976; 5: 377-95.

78 Norgan NG, Durnin JVGA. The effect of weeks of overfeeding on the body weight, body composition, and energy metabolism of young men. American Journal of Clinical Nutrition 1980; 33: 978-88.

79 Ferro-Luzzi A. Range of variation in energy expenditure and scope of regulation. In: Taylor TG, Jenkins NK, eds. Proceedings of XIII international congress of nutrition. London: John Libbey, 1985, 393-9.

80 Soares MJ, Shetty PS. Basal metabolic rates and metabolic efficiency in chronic undernutrition. European Journal of Clinical Nutrition 1991; 45: 363-73.

81 McNeill G, Rivers JPW, Payne PR, deBritto JJ, Abel R. Basal metabolic rate of Indian men: no evidence of metabolic adaptation to a low plan of nutrition. Human Nutrition: Clinical Nutrition 1987; 41C: 473-84.

82 Srikantia SG. Nutritional adaptation in man. Proceedings of the Nutritional Society of India 1985; 31: 1-16.

83 Shetty PS. Chronic undernutrition and metabolic adaptation. Proceedings of the Nutrition Society 1993; 52: 267-84.

84 Immink MDC. Economic effects of chronic energy deficiency. In: Schurch B, Scrimshaw NS, eds. Chronic energy deficiency: consequences and related issues. Switzerland: IDECG, 1987, 153-74.

85 Rutishauser IH, Whitehead RG. Energy intake and expenditure in 1-3 year old Ugandan children living in a rural environment. British Journal of Nutrition 1972; 28: 145-52.

86 Gorsky RD, Calloway DH. Activity pattern changes with decrease in food energy intakes. Human Biology 1983; 55 577-86.

87 Torun B, Flores R, Vitteri FE, Immink MDC, Diaz E. Energy supplementation and work performance: Summary of
INCAP studies. Proceedings of XIV International Congress of Nutrition. Seoul: Korean Nutrition Society, 1989, 306-9.

88 Ferro-Luzzi A, Sette S, Franklin M, James WPT. A simplified approach to assessing adult chronic energy deficiency. European Journal of Clinical Nutrition 1992; 46: 173-86.

89 Shetty PS, James WPT. Body mass index: a measure of chronic energy deficiency in adults. FAO food and nutrition Paper No. 56. Rome: FAO, 1994, 1-57.

90 Vitteri FE, Torun B. Energy intake and physical work in Guatemalan farmers. Bolitin de la Oficina Samtaria Panamericana (Spanish) 1975; 78: 58-74.

91 Whitehead RG, Rowland MG, Hutton M, Prentice AM, Muller E, Paul A. Factors influencing lactation performance in rural Gambian mothers. Lancet 1978; 2: 178-81.

92 Norgan NG, Ferro-Luzzi A. Human adaptation to energy undernutrition. In: Fregly MJ, Blatteis CM, eds. Handbook of physiology: Section 4. Environmental physiology Volume II. New York: Oxford University Press for the American Physiological Society, 1996, 1391-409.

93 Shetty PS. Adaptation to low energy intakes: the responses and limits to low intakes in infants, children and adults. European Journal Clinical Nutrition 1999; 53S: 14-33.

94 Lifson M, McClintock R. Theory of use of turnover rates of body water for measuring energy and maternal balance. Journal of Theoretical Biology 1966; 12: 46-74.

95 Schoeller DA. Measurement of energy expenditure in freeliving humans by using doubly labelled water. Journal of Nutrition 1988; 118: 1278-89.

96 Schoeller DA, van Santen E. Measurement of energy expenditure in humans by doubly labelled water method. American Journal of Physiology 1982; 53: 955-9.

97 Schoeller DA. Recent advances from application of doubly labelled water to measure human energy expenditure. Journal of Nutrition 1999; 129: 1765-8.

98 Coward WA. Contributions of the doubly labelled water method to studies of energy balance in the Third World. American Journal of Clinical Nutrition 1998; 68: S962-9.

99 Kurpad AV, Borgonha S, Shetty PS. Measurement of total energy expenditure by the doubly labelled water technique in free living Indians in Bangalore city. Indian Journal of Medical Research 1997; 105: 212-9.

100 Borgonha S, Shetty PS, Kurpad AV. Total energy expenditure and physical activity level in chronically energy deficient Indian males measured by the doubly labelled water technique. Indian Journal of Medical Research 2000; 111: 138-46.

101 Karvonen MJ, Pekkarinen M, Metsala P, Rautenen Y. Diet and serum cholesterol of lumberjacks. British Journal of Nutrition 1961; 15: 157-63.

102 Singh J, Prentice AM, Diaz E, Coward WA, Ashford J, Sawyer M, Whitehead RG. Energy expenditure of Gambian women during peak agricultural activity measured by the doublylabelled water method. British Journal of Nutrition 1989; 62: 315-29.

103 Carpenter WH, Poehlman ET, O'Connell M, Goran MI. Influence of body composition and resting metabolic rate on variation in total energy expenditure: a meta-analysis. American Journal of Clinical Nutrition 1995; 61: 4-10.

104 Goldberg GR, Black AE, Jebb SA, Cole TJ, Murgatroyd PR, Coward WA, Prentice AM. Critical evaluation of energy intake data using fundamental principles of energy physiology. Derivation of cut-off values to identify underrecording. European Journal of Clinical Nutrition 1991; 45 : 569-81.

105 Edholm OG. Energy expenditure and food intake. In: Apfelbaum M, ed. Energy balance in man. Paris: Masson, $1973,51-60$. 